\title{
Long noncoding RNAs: a potential novel class of cancer biomarkers
}

\author{
Aliaksandr A. Yarmishyn* and Igor V. Kurochkin* \\ Department of Genome and Gene Expression Data Analysis, Bioinformatics Institute, Agency for Science, Technology and \\ Research, Singapore, Singapore
}

Long noncoding RNAs (IncRNAs) are a novel class of RNA molecules defined as transcripts longer than 200 nucleotides that lack protein coding potential. They constitute a major, but still poorly characterized part of human transcriptome, however, evidence is growing that they are important regulatory molecules involved in various cellular processes. It is becoming increasingly clear that many IncRNAs are deregulated in cancer and some of them can be important drivers of malignant transformation. On

\section{OPEN ACCESS}

Edited by:

Richard D. Emes,

University of Nottingham, UK

Reviewed by:

Zhixiang Lu,

University of California, Los Angeles,

USA

Richard D. Emes,

University of Nottingham, UK

*Correspondence:

Aliaksandr A. Yarmishyn and Igor V. Kurochkin,

Department of Genome and Gene

Expression Data Analysis,

Bioinformatics Institute, Agency for

Science, Technology and Research,

Matrix 138671, Singapore, Singapore

aliaksandry@bii.a-star.edu.sg;

igork@bii.a-star.edu.sg

Specialty section:

This article was submitted to

Bioinformatics and Computational

Biology,

a section of the journal

Frontiers in Genetics

Received: 15 October 2014

Accepted: 27 March 2015

Published: 23 April 2015

Citation:

Yarmishyn AA and Kurochkin IV (2015) Long noncoding RNAs:

a potential novel class of cancer

biomarkers.

Front. Genet. 6:145.

doi: 10.3389/fgene.2015.00145 the one hand, some IncRNAs can have highly specific expression in particular types of cancer making them a promising tool for diagnosis. The expression of other IncRNAs can correlate with different pathophysiological features of tumor growth and with patient survival, thus making them convenient biomarkers for prognosis. In this review we outline the current state of knowledge about the fast growing field of application of IncRNAs as tumor biomarkers.

Keywords: long noncoding RNA, biomarkers, cancer

\section{Introduction}

The development of high resolution microarray and genome wide sequencing technologies allowed comprehensive characterization of mammalian transcriptomes. The main conclusion from the pioneering in-depth transcriptome studies performed by FANTOM (Functional Annotation Of Mouse genome) and ENCODE (Encyclopedia of DNA Elements) consortia was discovery of the pervasive transcription of the mouse and human genomes with protein coding mRNAs constituting only a minor fraction of the transcribed sequences (Okazaki et al., 2002; Carninci et al., 2005; Birney et al., 2007). The most recent data from ENCODE consortium indicates that around 70\% of human genome is transcribed, generating a vast range of noncoding RNAs (Djebali et al., 2012). Based on transcript size noncoding RNAs are classified into small noncoding RNAs ( $<200 \mathrm{nt})$ and long noncoding RNAs (lncRNAs; > $200 \mathrm{nt}$ ). Small noncoding RNAs, particularly miRNAs are well characterized as post-transcriptional regulators of mRNAs and have well established roles in cancer (Garzon et al., 2009; Fabian and Sonenberg, 2012; Kong et al., 2012).

On the other hand, lncRNAs still remain poorly characterized, however, evidence for their importance and functionality is mounting. The number of known lncRNA genes is still rising as the process of their annotation is ongoing. The current version of GENCODE (encyclopedia of genes and gene variants) includes 15,877 human lncRNA genes encoding 26,414 transcripts based on manual curation, computational analysis, and experimental validation (Version 21, June 2014 freeze, GRCh38 - Ensembl 77; Dunham et al., 2012; www.gencodegenes.org).

Long noncoding RNAs share common features with mRNAs, such as many of them are transcribed by RNA polymerase II, undergo splicing, polyadenylation, and $5^{\prime}$-capping (Table $\mathbf{1}$ ). Similarly, to protein coding genes, lncRNA genes have histone marks of active promoters 
TABLE 1 | Comparison of several important features of mRNAs and long noncoding RNAs (IncRNAs) based on GENCODE v7 catalog of human transcripts*.

\begin{tabular}{lll}
\hline Feature & mRNAs & IncRNAs \\
\hline Median transcript length & $2453 \mathrm{nt}$ & $592 \mathrm{nt}$ \\
Median number of exons & 3 & 8 \\
Expression levels & Higher & Lower \\
5' end supported by CAGE & $55 \%$ & $15 \%$ \\
3' end supported by polyA signal & $51 \%$ & $39 \%$ \\
Tissue specificity & Lower & Higher \\
Subcellular localization & Mostly cytoplasmic & Mostly nuclear \\
\hline
\end{tabular}

* The data shown in Table 1 are taken from Derrien et al. (2012).

(H3K4me2/3, H2K9ac, H3K27ac) and actively transcribed gene bodies (H3K36me3; Guttman et al., 2009; Derrien et al., 2012). On the other hand, lncRNAs have several distinct features that distinguish them from protein coding mRNAs (Table 1). LncRNAs generally lack or have very little open reading frames (ORFs). Commonly, lncRNA transcripts are shorter and have fewer exons. Unlike mRNAs, which are mostly transported to the cytoplasm, the majority of lncRNAs are localized to the nucleus (Derrien et al., 2012). LncRNAs demonstrate relatively lower expression levels than protein coding genes, however, they exhibit more specific tissue expression patterns (Derrien et al., 2012).

Contrary to the initial view that lncRNAs might be a mere transcriptional noise, several lines of evidence indicate to their functionality (Ponting and Belgard, 2010). Firstly, many lncRNAs demonstrate clear signs of evolutionary conservation and selection (Ponjavic et al., 2007; Guttman et al., 2009). Secondly, expression of many lncRNAs is developmentally and temporally regulated and restricted to certain tissues (Cawley et al., 2004; Ravasi et al., 2006; Mercer et al., 2008). It is becoming increasingly clear that lncRNAs are important regulatory molecules acting at different levels of gene expression, such as chromatin remodeling, transcription, stability, posttranscriptional modifications, and translation. For example, lncRNAs Xist and HOTAIR (HOX transcript antisense RNA) recruit chromatin remodeling complexes, such as Polycomb repressive complex 2 (PRC2) to induce heterochromatin state, thus repressing gene expression at target loci (Zhao et al., 2008; Gupta et al., 2010; Figure 1). Indeed, a considerable proportion of lncRNAs has been shown to associate with PRC2 complex, implying that it might be one of the prevalent mechanisms for their functionality (Khalil et al., 2009). LncRNAs directly regulate transcription by different mechanisms, such as via interaction with RNA binding proteins (Wang et al., 2008), repression of promoters (Martianov et al., 2007), acting as co-activators of transcription factors (Feng et al., 2006), or negatively regulating transcription factors by sequestration (Kino et al., 2010; Hung et al., 2011). At the level of pre-mRNA processing, lncRNA MALAT1 can regulate alternative splicing by interacting with several serine/arginine (SR) splicing factors (Tripathi et al., 2010).

Long noncoding RNAs can interact with mRNAs and modulate their translation both positively and negatively. For example, lincRNA-p21 interacts with JUNB and CTNNB1 mRNAs and selectively lowers their translation through a mechanism

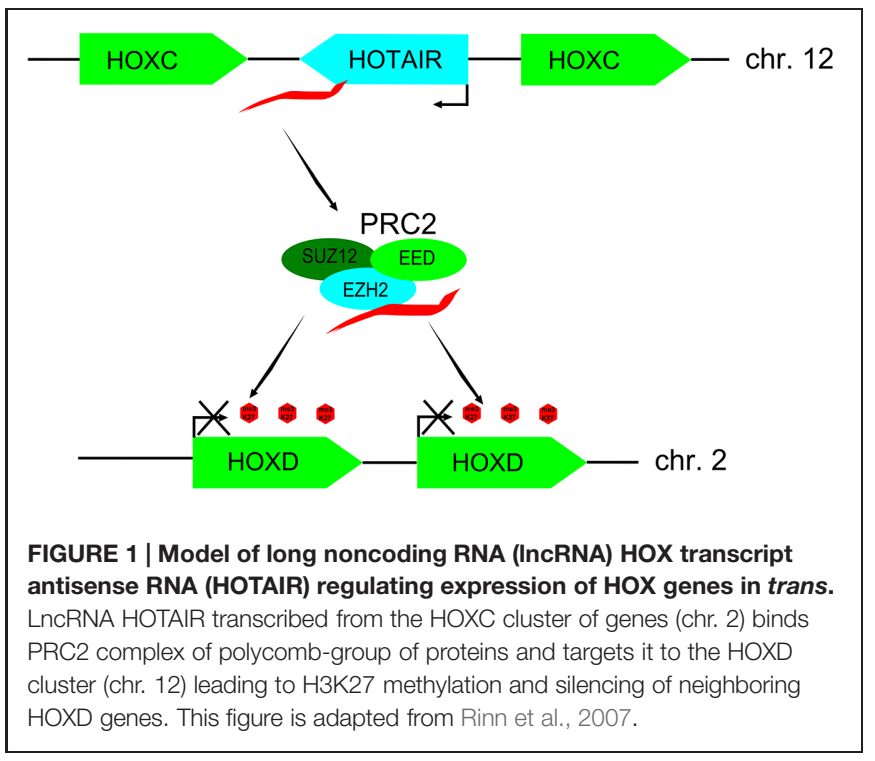

that includes reduced polysome sizes or ribosome 'drop-off' (Yoon et al., 2012). In contrast, lncRNA antisense to Uchl1 gene increases translation of UCHL1 protein in a mechanism dependent on a $5^{\prime}$ overlapping sequence and an embedded inverted SINEB2 element in lncRNA (Carrieri et al., 2012). LncRNA can also regulate stability of target mRNAs through imperfect base pairing between an Alu element in the $3^{\prime}$ UTR of a Staufen 1 (STAU1)-mediated mRNA decay target and another Alu element in a cytoplasmic lncRNA (Gong and Maquat, 2011). This imperfect base-pairing creates a lncRNA-mRNA duplex that binds STAU1 resulting in degradation of mRNA.

With the growing evidence of lncRNA functionality it is of no surprise that they are implicated in diverse pathologic conditions, including cancer. Various lncRNAs have been found to be differentially expressed in cancer and their enforced expression or knock down could result in altered phenotypical responses related to malignant transformation, such as changes in proliferation, invasive potential, or apoptosis. Similarly, to protein coding genes, lncRNAs can be classified into oncogenes and tumor suppressors. This opens opportunities for application of lncRNAs as biomarkers for cancer diagnosis and prognosis. Indeed, the functions of lncRNAs are more likely to correlate with their abundance as they do not encode proteins, making them highly suitable as biomarkers. In this review, we summarize the current knowledge about lncRNAs as potential diagnostic and prognostic biomarkers of cancer.

\section{Diagnostic Cancer Biomarkers}

The tissue specific nature of expression of lncRNAs, which is generally higher than that of protein coding mRNAs (Derrien et al., 2012), makes them potentially advantageous for identification of highly specific diagnostic biomarkers. Whereas some well known lncRNAs, such as HOTAIR are known to be deregulated in a wide spectrum of cancers, several lncRNAs have been described to be highly specific for a particular cancer type. 
For example, expression of lncRNA PCA3 (Prostate Cancer Antigen 3) is highly restricted to prostate tissue (Bussemakers et al., 1999). In the same study it was shown by differential display analysis that PCA3 is highly overexpressed in prostatic tumors in comparison with non-neoplastic prostatic tissue of the same patients. Moreover, its expression was not detected in other tumor types or cell lines (Bussemakers et al., 1999). PCGEM1 is another lncRNA gene with highly prostate tissue-specific expression. Interestingly, its elevated expression was associated with high risk groups, such as the African-American population, which is more susceptible to prostate cancer as compared to Caucasian-American or those individuals with family history of prostate cancer as compared to those without family history (Petrovics et al., 2004). Another lncRNA, encoded in 8q24 locus reported to be associated with prostate cancer susceptibility in European and African-American populations, termed PRNCR1 (prostate cancer noncoding RNA 1), was shown to be up-regulated in some of the prostate cancer cells as well as precursor lesion prostatic intraepithelial neoplasia (Chung et al., 2011).

HULC (highly up-regulated in liver cancer) has been identified as highly up-regulated in hepatocellular carcinoma (Panzitt et al., 2007) and colorectal carcinomas that produce liver metastases but not in the primary colon tumors or their non-liver metastases (Matouk et al., 2009). Interestingly, the specific genetic variant rs7763881 in HULC was found to be associated with decreased risk of HCC in persistent carriers of HBV (Liu et al., 2012).

Detection of cancer at the early stages significantly increases the chances of successful therapy. One of the ways for early diagnosis is the screening for biomarkers by non-invasive methods, such as sampling of extracellular fluids. A fraction of DNA and RNA molecules referred to as circulating nucleic acids (CNAs) are found in blood serum and other extracellular fluids. Changes in the levels of CNAs are associated with tumor burden and malignant progression, thus pointing to their potential as tumor biomarkers easily detected by PCR assays (Schwarzenbach et al., 2011). Several lncRNAs have been characterized as potential biomarkers in human body fluids. The most prominent example of such biomarkers is PCA3, a lncRNA highly expressed is prostate cancer (de Kok et al., 2002). The detection of PCA3 in the urine has been demonstrated to be a more specific marker to diagnose prostate cancer than the commonly used prostatespecific antigen (PSA) and already found wide application in clinics (Hessels et al., 2003; Tinzl et al., 2004; Lee et al., 2011). Similarly, UCA1 (urothelial carcinoma associated 1) transcript detected in urine was shown to be a highly sensitive and specific biomarker of bladder carcinoma (Wang et al., 2006). HULC was detected with high frequency in plasma of patients with hepatocellular carcinoma, making it a promising diagnostic biomarker for this type of cancer (Xie et al., 2013). Several other studies identify promising biomarkers for different types of cancer, such as MALAT1 derived fragment detected in plasma as a biomarker for prostate cancer (Ren et al., 2013), AA174084 found in gastric juice as indicator of gastric cancer (Shao et al., 2014), a set of salivary lncRNAs as potential markers for oral squamous cell carcinoma diagnosis (Tang et al., 2013).
Exosomes are nanovesicles secreted into the extracellular environment from the cells upon fusion of intracellular vesicles with the plasma membrane (Raposo and Stoorvogel, 2013). The molecular content of exosomes replicates that of the releasing cell and reflects its status. The abundance of exosomes in body fluids and possibility to detect tumor specific material of their parental cancer cells makes exosomes a promising tool for non-invasive diagnostics (Properzi et al., 2013). The content of exosomes comprises different kinds of RNA, including lncRNAs (Jenjaroenpun et al., 2013). Indeed, IncRNAs are highly enriched in exosomes compared to donor cells (Batagov et al., 2011; Gezer et al., 2014). For example, lncRNA TUC339 was found to be highly enriched in extracellular vesicles secreted from hepatocellular carcinoma cells where it modulated tumor cell growth and adhesion (Kogure et al., 2013). LincRNA-ROR, another IncRNA from hepatocellular carcinoma derived extracellular vesicles was shown to modulate chemotherapeutic response in this type of cancer (Takahashi et al., 2014). Given the fact that most transcriptome studies aimed to identify biomarkers were focused on miRNAs, shifting the focus to more unbiased characterization that would include other types of transcripts present in cancer derived exosomes would potentially lead to discovery of more lncRNA based biomarkers.

\section{Prognostic Cancer Biomarkers}

Different lncRNAs were shown to be aberrantly expressed in cancer and correlate with tumorigenesis, tumor progression, and metastatic properties in various cancer conditions. Such lncRNA can be involved in both oncogenic and tumor suppressor pathways and their expression can correlate with good or bad prognosis, making them promising prognostic biomarkers (Table 2).

HOTAIR is one of the most well studied examples of lncRNA implicated in cancer (Wu et al., 2014a). Initially it was identified by Gupta et al. (2010) to be highly overexpressed in primary and metastatic breast cancer tissues as compared to normal breast epithelium. High HOTAIR expression level in primary tumors was shown to be a significant predictor of eventual metastasis and death (Gupta et al., 2010). Enforced expression of HOTAIR in breast carcinoma cells induced genome wide retargeting of PRC2 and, as a result, altered H3K27 methylation and gene expression patterns, increased invasiveness, and metastasis (Gupta et al., 2010). Interestingly, BRCA1, an important suppressor of breast cancer inhibits HOTAIR dependent PRC2 activity by competitive binding to its catalytic subunit EZH2 (Wang et al., 2013). In another breast cancer study it was shown that HOTAIR is regulated by oestradiol in estrogen receptor dependent manner (Bhan et al., 2013).

HOTAIR was also shown to be involved in hepatocellular carcinoma (Geng et al., 2011; Yang et al., 2011; Ishibashi et al., 2013). Overexpression of HOTAIR in tumor tissues was reported to be associated with increased risk of recurrence after hepatectomy, as well as positively correlate with lymph node metastasis (Geng et al., 2011). Similarly, increased HOTAIR was shown to be prognostic factor of tumor recurrence following liver transplantation (Yang et al., 2011). In the same study, knock down of HOTAIR 
TABLE 2 | IncRNAs with cancer biomarker potential.

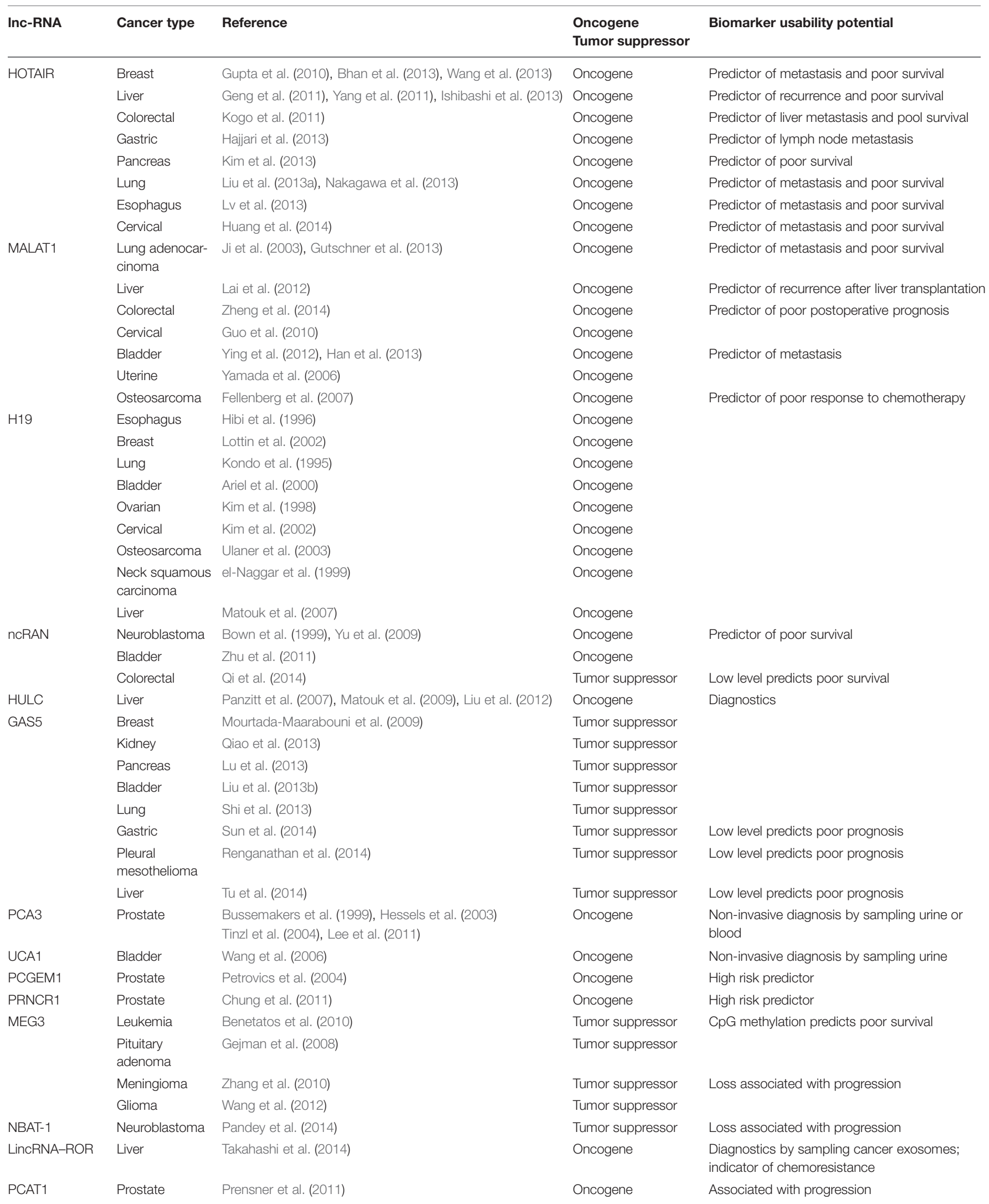


in HCC cell line reduced cell viability and invasion, as well as increased sensitivity to cisplatin and doxorubicin (Yang et al., 2011). Patients with overexpressed HOTAIR had poorer prognoses and larger tumor sizes, more rapid proliferation of tumor cells (Ishibashi et al., 2013).

In colorectal carcinoma high expression of HOTAIR was also shown to correlate with poor prognosis and liver metastasis (Kogo et al., 2011). Positive correlation between expression levels of HOTAIR, the members of PRC2 complex, Suz12, and Ezh2, and $\mathrm{H} 3 \mathrm{~K} 27 \mathrm{me} 3$ chromatin marks suggests the role of HOTAIR in PRC2 mediated chromatin reprogramming in metastasis (Kogo et al., 2011). Apart from the primary tumors, HOTAIR was also shown to be a negative prognostic factor in the blood of colorectal patients suggesting that measuring the HOTAIR blood levels may provide a minimally invasive test to identify patients with unfavorable prognosis (Svoboda et al., 2014). High expression of HOTAIR associated with advanced stage, lymphatic node metastasis and poor survival was also reported in gastric cancer (Endo et al., 2013; Hajjari et al., 2013; Xu et al., 2013). The increased expression level of HOTAIR positively correlates with Suz12, implying PRC2 dependent mechanism of epigenetic reprogramming in oncogenicity of gastric carcinoma (Hajjari et al., 2013). Also HOTAIR was shown to act as an endogenous sponge of miR-331-3p miRNA, thus abolishing repression of its target HER2, implicated in development of gastric cancer (Liu et al., 2014). In addition to the above described, HOTAIR was reported to be a negative prognosis biomarker for a number of other malignancies, such as pancreatic cancer (Kim et al., 2013), lung cancer (Liu et al., 2013a; Nakagawa et al., 2013), esophageal carcinoma (Lv et al., 2013), cervical cancer (Huang et al., 2014), and colon cancer (Wu et al., 2014b). A meta-analysis study of prognostic capability of HOTAIR in different types of cancer revealed that it is a more reliable predictor of overall survival in patients with digestive system malignancies (Zhang et al., 2014).

Another paradigmal case of lncRNA based cancer biomarkers is MALAT1 (Metastasis-associated Lung Adenocarcinoma Transcript 1). As its name implies, it was discovered as a predictive marker of metastasis development in early stage lung adenocarcinoma (Ji et al., 2003). In a MALAT1 knockout model of human lung cancer cells it was shown that MALAT1 regulates metastatic signature of genes (Gutschner et al., 2013). In such model metastatic capacities of lung adenocarcinoma mouse xenografts were significantly compromised (Gutschner et al., 2013). In the same study, targeting MALAT1 with antisense nucleotides significantly reduced metastasis making it an interesting target for therapy (Gutschner et al., 2013).

In hepatocellular carcinoma (HCC) MALAT1 overexpression is a predictive factor for tumor recurrence following liver transplantation (Lai et al., 2012). The depletion of MALAT1 by siRNA in HepG2 cell line resulted in reduction of cell viability, mobility and invasiveness, as well as increase of sensitivity to apoptosis (Lai et al., 2012). High expression of MALAT1 was shown to be a marker of poor postoperative prognosis in colorectal carcinoma (Zheng et al., 2014). Moreover, the obvious oncogenic role of MALAT1 was demonstrated in a number of other cancer models, including bladder cancer (Ying et al., 2012; Han et al., 2013), cervical cancer (Guo et al., 2010), uterine sarcoma (Yamada et al., 2006), and osteosarcoma (Fellenberg et al., 2007).

H19 is IncRNA expressed from the maternal allele that plays an important role in genomic imprinting during growth and development (Gabory et al., 2010). Loss of imprinting at the H19 locus in paternal allele results in biallelic expression and, therefore, elevated H19 levels in a wide range of cancers (Kondo et al., 1995; Hibi et al., 1996; Kim et al., 1998; el-Naggar et al., 1999; Ariel et al., 2000; Müller et al., 2000; Kim et al., 2002; Lottin et al., 2002; Ulaner et al., 2003). High expression of H19 was shown to be associated with a range of risk factors, such as smoking, exposure to carcinogens and hypoxia (Matouk et al., 2007). Indeed, hypoxia causes up-regulation of H19 in cell lines with mutated p53 (Matouk et al., 2010). H19 is also directly induced by MYC oncogene in different cell lines (Barsyte-Lovejoy et al., 2006). Further adding to the host of oncogenic pathways with the involvement of $\mathrm{H} 19$, it serves as a precursor of miR-675, miRNA that down-regulates RB1 tumor suppressor transcript in colorectal cancer (Tsang et al., 2010).

NcRAN (noncoding RNA expressed in aggressive neuroblastoma) is encoded by a gene mapped to chromosome arm $17 \mathrm{q}$, whose amplification is one of the most common genetic abnormalities associated with poor prognosis in neuroblastoma (Bown et al., 1999; Yu et al., 2009). Indeed, the high expression levels of ncRAN were significantly associated with poor prognosis of the neuroblastoma patients (Yu et al., 2009). In addition, ncRAN was found to be upregulated in bladder cancer as compared to normal tissues and confer a set of oncogenic properties, such as increased cell proliferation, migration, and invasion (Zhu et al., 2011). In contrast, down-regulation of ncRAN was shown to be associated with metastatic properties and predict poor overall survival in colorectal carcinoma (Qi et al., 2014).

In addition to lncRNAs with pronounced oncogenic effects, which positively correlate with poor prognosis, a few lncRNAs have been characterized to act as tumor suppressors. One such example is GAS5 (growth arrest-specific 5), a tumor suppressor lncRNA which reduces growth, metabolism, and sensitizes cells to apoptosis by inhibiting glucocorticoid receptor (Kino et al., 2010). GAS5 is down-regulated in a number of cancers, such as breast cancer (Mourtada-Maarabouni et al., 2009), renal cell carcinoma (Qiao et al., 2013), pancreatic cancer (Lu et al., 2013), bladder cancer (Liu et al., 2013b), non-small-cell lung cancer (Shi et al., 2013), gastric cancer (Sun et al., 2014), malignant pleural mesothelioma (Renganathan et al., 2014), hepatocellular carcinoma (Tu et al., 2014). Low level of GAS5 indicates a poor prognosis in cancer patients (Sun et al., 2014; Tu et al., 2014).

Another example of a tumor suppressor lncRNA is lincRNAp21. This lncRNA was shown to be directly induced by p53 and play a crucial role in p53 mediated transcriptional response (Huarte et al., 2010). Maternally expressed gene 3 (MEG3) is another prominent tumor suppressor lncRNA that acts by increasing p53 activity on specific transcription targets (Zhou et al., 2007). Besides, MEG3 is able to inhibit cell proliferation 
in the absence of p53 suggesting that this lncRNA may act also via p53-independent pathway (Zhou et al., 2007). Consistently, MEG3 is down-regulated in a number of cancers, including myeloid leukemia (Benetatos et al., 2010), pituitary adenoma (Gejman et al., 2008), meningioma (Zhang et al., 2010), and glioma (Wang et al., 2012).

In conclusion, IncRNAs may act both as oncogenes and tumor suppressors without obvious prevalence of one class over another. In this respect lncRNAs behave similarly, to protein-coding transcripts.

\section{Prognostic Expression Signatures Based on IncRNAs}

Characterizing tumor transcriptomes at the system's level allows identification of molecular subtypes of cancer and development of predictive and prognostic gene expression signatures. Microarrays have been widely used for the past two decades in preclinical research to characterize tumor gene expression profiles on a genome-wide scale. Most of these signatures were based on protein coding genes as little was known about lncRNAs and their important roles in cancer. However, the widely used commercial microarray platforms in addition to protein coding mRNAs were designed to detect numerous ESTs and nonannotated RNAs. Many of these transcripts are now annotated as bona fide lncRNAs, therefore the vast collection of microarray datasets accumulated during the past two decades provides a valuable resource for identification of novel gene expression signatures and biomarkers based on lncRNAs. In our recent study we annotated probe sets detecting IncRNAs on widely used Affymetrix U133 series of microarray platforms by using two approaches: firstly by matching probe sets to Gencode database of lncRNAs and secondly by developing a stringent in silico protein coding potential prediction filter (Yarmishyn et al., 2014). Affymetrix U133 microarrays have been found to contain probe sets for the measurement of 1581 lncRNAs (Yarmishyn et al., 2014). Using this resource and previously deposited microarraybased data on expression profiling of neuroblastic tumors we identified 159 lncRNA signature that discriminates between localized and metastatic stages of neuroblastoma, as well as between relapsing and non-relapsing primary tumors (Yarmishyn et al., 2014). The data mining of Affymetrix U133 Plus datasets was also applied to identify lncRNA signatures associated with different histological subtypes and malignancy grades of glioma (Zhang et al., 2012). In the follow up study, the six-lncRNA prognostic signature of glioma significantly associated with overall survival was identified (Zhang et al., 2013). In another study the classification of glioma into three molecular subtypes based on IncRNA expression profiles was proposed (Li et al., 2014). Similarly, using lncRNA mining approach, Hu et al. (2014) identified six lncRNA prognostic signature significantly associated with disease free survival in colorectal carcinoma. LncRNA-based expression profiles were also utilized to classify colorectal cancer samples into five distinct molecular subtypes, each characterized by distinct biological pathways and clinical outcome (Chen et al., 2014).
As high throughput sequencing technology becomes cheaper and more accessible we might expect the influx of de novo data from transcriptome sequencing and identification of new biomarkers and diagnostic signatures. For example, Prensner et al. (2011) utilized RNA-Seq approach to identify 121 lncRNAs associated with prostate cancer progression in a cohort of 102 patients. One of these IncRNAs PCAT-1 was further characterized as a regulator of proliferation in prostate cancer cells (Prensner et al., 2011). In a similar study the sequencing of transcriptomes of high and low risk neuroblastoma identified a set of differentially expressed lncRNAs. One of them NBAT- 1 was characterized as a tumor suppressor, whose loss contributes to aggressive neuroblastoma by increasing proliferation and impairing differentiation (Pandey et al., 2014). RNA-Seq analysis was also employed by White et al. (2014) to detect lncRNAs associated with lung cancer. In this study the transcriptome sequencing data from a cohort of 567 patients were used to identify 111 novel IncRNAs differentially regulated between tumor and adjacent normal tissue samples. Further meta-analysis revealed that a subset of these lncRNAs was deregulated in a broad range of tumors and another subset was highly deregulated specifically in lung cancers, making the latter a promising source of biomarkers (White et al., 2014).

\section{Concluding Remarks}

The last decade witnessed a vast expansion of knowledge regarding $\operatorname{lncRNAs}$ and their important roles in regulation of various biological processes and development of disease. A number of IncRNAs, such as HOTAIR, MALAT and H19 were found to be aberrantly expressed in a number of cancers and extensively characterized as important players affecting the hallmark events of carcinogenesis, such as proliferation, apoptosis, and metastasis. These examples demonstrate that lncRNAs, on par with protein coding genes and miRNAs, have a great potential to be used as cancer biomarkers. Indeed, since lncRNAs are implicated in cancer biology at the level of RNA unlike mRNAs, which represent an intermediate on the way to functioning protein, their levels of expression are more likely to correlate with cancer phenotypes. Also, since proteins and lncRNAs represent different regulatory realms, their combination might increase each other's power as diagnostic and prognostic tools. It should be noted that the few examples described in this review are just a tip of the iceberg, as the field of lncRNAs is currently evolving and the work of annotation and characterization of lncRNAs is ongoing. With the deep sequencing technology becoming cheaper and more accessible one might expect an explosive growth of newly identified lncRNAs differentially expressed in cancers and associated with various clinical parameters.

\section{Acknowledgment}

We thank Thomas Derrien and Rory Johnson for sharing the numerical data for the numbers of exons in lncRNAs and mRNAs, which was necessary for compiling Table 1. 


\section{References}

Ariel, I., Sughayer, M., Fellig, Y., Pizov, G., Ayesh, S., Podeh, D., et al. (2000). The imprinted $\mathrm{H} 19$ gene is a marker of early recurrence in human bladder carcinoma. Mol. Pathol. 53, 320-323. doi: 10.1136/mp.53.6.320

Barsyte-Lovejoy, D., Lau, S. K., Boutros, P. C., Khosravi, F., Jurisica, I., Andrulis, I. L., et al. (2006). The c-Myc oncogene directly induces the H19 noncoding RNA by allele-specific binding to potentiate tumorigenesis. Cancer Res. 66, 5330-5337. doi: 10.1158/0008-5472.CAN-06-0037

Batagov, A. O., Kuznetsov, V. A., and Kurochkin, I. V. (2011). Identification of nucleotide patterns enriched in secreted RNAs as putative cis-acting elements targeting them to exosome nano-vesicles. BMC Genomics 12(Suppl. 3):S18. doi: 10.1186/1471-2164-12-S3-S18

Benetatos, L., Hatzimichael, E., Dasoula, A., Dranitsaris, G., Tsiara, S., Syrrou, M., et al. (2010). CpG methylation analysis of the MEG3 and SNRPN imprinted genes in acute myeloid leukemia and myelodysplastic syndromes. Leuk. Res. 34, 148-153. doi: 10.1016/j.leukres.2009.06.019

Bhan, A., Hussain, I., Ansari, K. I., Kasiri, S., Bashyal, A., and Mandal, S. S. (2013). Antisense transcript long noncoding RNA (lncRNA) HOTAIR is transcriptionally induced by estradiol. J. Mol. Biol. 425, 3707-3722. doi: 10.1016/j.jmb.2013.01.022

Birney, E., Stamatoyannopoulos, J. A., Dutta, A., Guigó, R., Gingeras, T. R., Margulies, E. H., et al. (2007). Identification and analysis of functional elements in $1 \%$ of the human genome by the ENCODE pilot project. Nature 447, 799-816. doi: 10.1038/nature05874

Bown, N., Cotterill, S., Lastowska, M., O’Neill, S., Pearson, A. D., Plantaz, D., et al. (1999). Gain of chromosome arm $17 \mathrm{q}$ and adverse outcome in patients with neuroblastoma. N. Engl. J. Med. 340, 1954-1961. doi: 10.1056/NEJM199906243402504

Bussemakers, M. J., van Bokhoven, A., Verhaegh, G. W., Smit, F. P., Karthaus, H. F., Schalken, J. A., et al. (1999). DD3: a new prostate-specific gene, highly overexpressed in prostate cancer. Cancer Res. 59, 5975-5979.

Carninci, P., Kasukawa, T., Katayama, S., Gough, J., Frith, M. C., Maeda, N., et al. (2005). The transcriptional landscape of the mammalian genome. Science 309, 1559-1563. doi: 10.1126/science.1112014

Carrieri, C., Cimatti, L., Biagioli, M., Beugnet, A., Zucchelli, S., Fedele, S., et al. (2012). Long noncoding antisense RNA controls Uchl1 translation through an embedded SINEB2 repeat. Nature 491, 454-457. doi: 10.1038/natur e11508

Cawley, S., Bekiranov, S., Ng, H. H., Kapranov, P., Sekinger, E. A., Kampa, D., et al. (2004). Unbiased mapping of transcription factor binding sites along human chromosomes 21 and 22 points to widespread regulation of noncoding RNAs. Cell 116, 499-509. doi: 10.1016/S0092-8674(04)00127-8

Chen, H., Xu, J., Hong, J., Tang, R., Zhang, X., and Fang, J. Y. (2014). Long noncoding RNA profiles identify five distinct molecular subtypes of colorectal cancer with clinical relevance. Mol. Oncol. 8, 1393-403. doi: 10.1016/j.molonc.2014.05.010

Chung, S., Nakagawa, H., Uemura, M., Piao, L., Ashikawa, K., Hosono, N., et al. (2011). Association of a novel long noncoding RNA in 8q24 with prostate cancer susceptibility. Cancer Sci. 102, 245-252. doi: 10.1111/j.13497006.2010.01737.x

de Kok, J. B., Verhaegh, G. W., Roelofs, R. W., Hessels, D., Kiemeney, L. A., Aalders, T. W., et al. (2002). DD3(PCA3), a very sensitive and specific marker to detect prostate tumors. Cancer Res. 62, 2695-2698.

Derrien, T., Johnson, R., Bussotti, G., Tanzer, A., Djebali, S., Tilgner, H., et al. (2012). The GENCODE v7 catalog of human long noncoding RNAs: analysis of their gene structure, evolution, and expression. Genome Res. 22, 1775-1789. doi: 10.1101/gr.132159.111

Djebali, S., Davis, C. A., Merkel, A., Dobin, A., Lassmann, T., Mortazavi, A., et al. (2012). Landscape of transcription in human cells. Nature 489, 101-108. doi: 10.1038 /nature 11233

Dunham, I., Kundaje, A., Aldred, S. F., Collins, P. J., Davis, C. A., Doyle, F., et al. (2012). An integrated encyclopedia of DNA elements in the human genome. Nature 489, 57-74. doi: 10.1038/nature11247

el-Naggar, A. K., Lai, S., Tucker, S. A., Clayman, G. L., Goepfert, H., Hong, W. K., et al. (1999). Frequent loss of imprinting at the IGF2 and H19 genes in head and neck squamous carcinoma. Oncogene 18, 7063-7069. doi: $10.1038 /$ sj.onc. 1203192
Endo, H., Shiroki, T., Nakagawa, T., Yokoyama, M., Tamai, K., Yamanami, H., et al. (2013). Enhanced expression of long noncoding RNA HOTAIR is associated with the development of gastric cancer. PLOS ONE 8:e77070. doi: 10.1371/journal.pone.0077070

Fabian, M. R., and Sonenberg, N. (2012). The mechanics of miRNA-mediated gene silencing: a look under the hood of miRISC. Nat. Struct. Mol. Biol. 19, 586-593. doi: $10.1038 /$ nsmb. 2296

Fellenberg, J., Bernd, L., Delling, G., Witte, D., and Zahlten-Hinguranage, A. (2007). Prognostic significance of drug-regulated genes in high-grade osteosarcoma. Mod. Pathol. 20, 1085-1094. doi: 10.1038/modpathol.3800937

Feng, J., Bi, C., Clark, B. S., Mady, R., Shah, P., and Kohtz, J. D. (2006). The Evf2 noncoding RNA is transcribed from the Dlx-5/6 ultraconserved region and functions as a Dlx-2 transcriptional coactivator. Genes Dev. 20, 1470-1484. doi: $10.1101 /$ gad.1416106

Gabory, A., Jammes, H., and Dandolo, L. (2010). The H19 locus: role of an imprinted noncoding RNA in growth and development. Bioessays 32, 473-480. doi: 10.1002/bies.200900170

Garzon, R., Calin, G. A., and Croce, C. M. (2009). MicroRNAs in Cancer. Annu. Rev. Med. 60, 167-179. doi: 10.1146/annurev.med.59.053006.104707

Gejman, R., Batista, D. L., Zhong, Y., Zhou, Y., Zhang, X., Swearingen, B., et al. (2008). Selective loss of MEG3 expression and intergenic differentially methylated region hypermethylation in the MEG3/DLK1 locus in human clinically nonfunctioning pituitary adenomas. J. Clin. Endocrinol. Metab. 93, 4119-4125. doi: 10.1210/jc.2007-2633

Geng, Y. J., Xie, S. L., Li, Q., Ma, J., and Wang, G. Y. (2011). Large intervening noncoding RNA HOTAIR is associated with hepatocellular carcinoma progression. J. Int. Med. Res. 39, 2119-2128. doi: 10.1177/147323001103900608

Gezer, U., Özgür, E., Cetinkaya, M., Isin, M., and Dalay, N. (2014). Long noncoding RNAs with low expression levels in cells are enriched in secreted exosomes. Cell Biol. Int. 38, 1076-1079. doi: 10.1002/cbin.10301

Gong, C., and Maquat, L. E. (2011). IncRNAs transactivate STAU1-mediated mRNA decay by duplexing with 3' UTRs via Alu elements. Nature 470, 284-288. doi: 10.1038/nature09701

Guo, F., Li, Y., Liu, Y., Wang, J., Li, Y., and Li, G. (2010). Inhibition of metastasisassociated lung adenocarcinoma transcript 1 in CaSki human cervical cancer cells suppresses cell proliferation and invasion. Acta Biochim. Biophys. Sin. (Shanghai) 42, 224-229. doi: 10.1093/abbs/gmq008

Gupta, R. A., Shah, N., Wang, K. C., Kim, J., Horlings, H. M., Wong, D. J., et al. (2010). Long noncoding RNA HOTAIR reprograms chromatin state to promote cancer metastasis. Nature 464, 1071-1076. doi: 10.1038/nature08975

Gutschner, T., Hämmerle, M., Eissmann, M., Hsu, J., Kim, Y., Hung, G., et al. (2013). The noncoding RNA MALAT1 is a critical regulator of the metastasis phenotype of lung cancer cells. Cancer Res. 73, 1180-1189. doi: 10.1158/00085472.CAN-12-2850

Guttman, M., Amit, I., Garber, M., French, C., Lin, M. F., Feldser, D., et al. (2009). Chromatin signature reveals over a thousand highly conserved large noncoding RNAs in mammals. Nature 458, 223-227. doi: 10.1038/nature07672

Hajjari, M., Behmanesh, M., Sadeghizadeh, M., and Zeinoddini, M. (2013). Upregulation of HOTAIR long noncoding RNA in human gastric adenocarcinoma tissues. Med. Oncol. 30:670. doi: 10.1007/s12032-013-0670-0

Han, Y., Liu, Y., Nie, L., Gui, Y., and Cai, Z. (2013). Inducing cell proliferation inhibition, apoptosis, and motility reduction by silencing long noncoding ribonucleic acid metastasis-associated lung adenocarcinoma transcript 1 in urothelial carcinoma of the bladder. Urology 81, 209.e1-209.e7. doi: 10.1016/j.urology.2012.08.044

Hessels, D., Klein Gunnewiek, J. M., van Oort, I., Karthaus, H. F., van Leenders, G. J., van Balken, B., et al. (2003). DD3(PCA3)-based molecular urine analysis for the diagnosis of prostate cancer. Eur. Urol. 44, 8-15. doi: 10.1016/S03022838(03)00201-X

Hibi, K., Nakamura, H., Hirai, A., Fujikake, Y., Kasai, Y., Akiyama, S., et al. (1996). Loss of H19 imprinting in esophageal cancer. Cancer Res. 56, 480-482.

Hu, Y., Chen, H. Y., Yu, C. Y., Xu, J., Wang, J. L., Qian, J., et al. (2014). A long noncoding RNA signature to improve prognosis prediction of colorectal cancer. Oncotarget 5, 2230-2242.

Huang, L., Liao, L. M., Liu, A. W., Wu, J. B., Cheng, X. L., Lin, J. X., et al. (2014). Overexpression of long noncoding RNA HOTAIR predicts a poor prognosis in patients with cervical cancer. Arch. Gynecol. Obstet. 290, 717-723. doi: 10.1007/s00404-014-3236-2 
Huarte, M., Guttman, M., Feldser, D., Garber, M., Koziol, M. J., KenzelmannBroz, D., et al. (2010). A large intergenic noncoding RNA induced by p53 mediates global gene repression in the p53 response. Cell 142, 409-419. doi: 10.1016/j.cell.2010.06.040

Hung, T., Wang, Y., Lin, M. F., Koegel, A. K., Kotake, Y., Grant, G. D., et al. (2011). Extensive and coordinated transcription of noncoding RNAs within cell-cycle promoters. Nat. Genet. 43, 621-629. doi: 10.1038/ng.848

Ishibashi, M., Kogo, R., Shibata, K., Sawada, G., Takahashi, Y., Kurashige, J., et al. (2013). Clinical significance of the expression of long noncoding RNA HOTAIR in primary hepatocellular carcinoma. Oncol. Rep. 29, 946-950. doi: 10.3892/or.2012.2219

Jenjaroenpun, P., Kremenska, Y., Nair, V. M., Kremenskoy, M., Joseph, B., and Kurochkin, I. V. (2013). Characterization of RNA in exosomes secreted by human breast cancer cell lines using next-generation sequencing. Peer J. 1:e201. doi: $10.7717 /$ peerj.201

Ji, P., Diederichs, S., Wang, W., Böing, S., Metzger, R., Schneider, P. M., et al. (2003). MALAT-1, a novel noncoding RNA, and thymosin beta4 predict metastasis and survival in early-stage non-small cell lung cancer. Oncogene 22, 8031-8041. doi: 10.1038/sj.onc. 1206928

Khalil, A. M., Guttman, M., Huarte, M., Garber, M., Raj, A., Rivea Morales, D., et al. (2009). Many human large intergenic noncoding RNAs associate with chromatin-modifying complexes and affect gene expression. Proc. Natl. Acad. Sci. U.S.A. 106, 11667-11672. doi: 10.1073/pnas.0904715106

Kim, H. T., Choi, B. H., Niikawa, N., Lee, T. S., and Chang, S. I. (1998). Frequent loss of imprinting of the H19 and IGF-II genes in ovarian tumors. Am. J. Med. Genet. 80, 391-395. doi: 10.1002/(SICI)1096-8628(19981204)80:4<391::AIDAJMG16>3.0.CO;2-H

Kim, K., Jutooru, I., Chadalapaka, G., Johnson, G., Frank, J., Burghardt, R., et al. (2013). HOTAIR is a negative prognostic factor and exhibits prooncogenic activity in pancreatic cancer. Oncogene 32, 1616-1625. doi: 10.1038/onc. 2012.193

Kim, S. J., Park, S. E., Lee, C., Lee, S. Y., Jo, J. H., Kim, J. M., et al. (2002). Alterations in promoter usage and expression levels of insulin-like growth factor-II and H19 genes in cervical carcinoma exhibiting biallelic expression of IGF-II. Biochim. Biophys. Acta 1586, 307-315. doi: 10.1016/S0925-4439(01) 00109-0

Kino, T., Hurt, D. E., Ichijo, T., Nader, N., and Chrousos, G. P. (2010). Noncoding RNA gas5 is a growth arrest- and starvation-associated repressor of the glucocorticoid receptor. Sci. Signal. 3:ra8. doi: 10.1126/scisignal. 2000568

Kogo, R., Shimamura, T., Mimori, K., Kawahara, K., Imoto, S., Sudo, T., et al. (2011). Long noncoding RNA HOTAIR regulates polycomb-dependent chromatin modification and is associated with poor prognosis in colorectal cancers. Cancer Res. 71, 6320-6326. doi: 10.1158/0008-5472.CAN-11-1021

Kogure, T., Yan, I. K., Lin, W. L., and Patel, T. (2013). Extracellular vesicle-mediated transfer of a novel long noncoding RNA TUC339: a mechanism of intercellular signaling in human hepatocellular cancer. Genes Cancer 4, 261-272. doi: $10.1177 / 1947601913499020$

Kondo, M., Suzuki, H., Ueda, R., Osada, H., Takagi, K., Takahashi, T., et al. (1995). Frequent loss of imprinting of the $\mathrm{H} 19$ gene is often associated with its overexpression in human lung cancers. Oncogene 10, 1193-1198.

Kong, Y. W., Ferland-McCollough, D., Jackson, T. J., and Bushell, M. (2012). microRNAs in cancer management. Lancet Oncol. 13:e249-e258. doi: 10.1016/S1470-2045(12)70073-6

Lai, M. C., Yang, Z., Zhou, L., Zhu, Q. Q., Xie, H. Y., Zhang, F., et al. (2012). Long noncoding RNA MALAT-1 overexpression predicts tumor recurrence of hepatocellular carcinoma after liver transplantation. Med. Oncol. 29, 1810-1816. doi: 10.1007/s12032-011-0004-Z

Lee, G. L., Dobi, A., and Srivastava, S. (2011). Prostate cancer: diagnostic performance of the PCA3 urine test. Nat. Rev. Urol. 8, 123-124. doi: 10.1038/nrurol.2011.10

Li, R., Qian, J., Wang, Y. Y., Zhang, J. X., and You, Y. P. (2014). Long noncoding RNA profiles reveal three molecular subtypes in glioma. CNS Neurosci. Ther. 20, 339-343. doi: 10.1111/cns.12220

Liu, X. H., Liu, Z. L., Sun, M., Liu, J., Wang, Z. X., and De, W. (2013a). The long noncoding RNA HOTAIR indicates a poor prognosis and promotes metastasis in non-small cell lung cancer. BMC Cancer 13:464. doi: 10.1186/1471-2407$13-464$
Liu, Z., Wang, W., Jiang, J., Bao, E., Xu, D., Zeng, Y., et al. (2013b). Downregulation of GAS5 promotes bladder cancer cell proliferation, partly by regulating CDK6. PLoS ONE 8:e73991. doi: 10.1371/journal.pone.0073991

Liu, X. H., Sun, M., Nie, F. Q., Ge, Y. B., Zhang, E. B., Yin, D. D., et al. (2014). Lnc RNA HOTAIR functions as a competing endogenous RNA to regulate HER2 expression by sponging miR-331-3p in gastric cancer. Mol. Cancer 13, 92. doi: 10.1186/1476-4598-13-92.

Liu, Y., Pan, S., Liu, L., Zhai, X., Liu, J., Wen, J., et al. (2012). A genetic variant in long noncoding RNA HULC contributes to risk of HBV-related hepatocellular carcinoma in a Chinese population. PLoS ONE 7:e35145. doi: 10.1371/journal.pone.0035145

Lottin, S., Adriaenssens, E., Dupressoir, T., Berteaux, N., Montpellier, C., Coll, J., et al. (2002). Overexpression of an ectopic H19 gene enhances the tumorigenic properties of breast cancer cells. Carcinogenesis 23, 1885-1895. doi: $10.1093 / \mathrm{carcin} / 23.11 .1885$

Lu, X., Fang, Y., Wang, Z., Xie, J., Zhan, Q., Deng, X., et al. (2013). Downregulation of gas 5 increases pancreatic cancer cell proliferation by regulating CDK6. Cell Tissue Res. 354, 891-896. doi: 10.1007/s00441-013-1711-x

Lv, X. B., Lian, G. Y., Wang, H. R., Song, E., Yao, H., and Wang, M. H. (2013). Long noncoding RNA HOTAIR is a prognostic marker for esophageal squamous cell carcinoma progression and survival. PLOS ONE 8:e63516. doi: 10.1371/journal.pone.0063516

Martianov, I., Ramadass, A., Serra Barros, A., Chow, N., and Akoulitchev, A. (2007). Repression of the human dihydrofolate reductase gene by a noncoding interfering transcript. Nature 445, 666-670. doi: 10.1038/nature05519

Matouk, I. J., Abbasi, I., Hochberg, A., Galun, E., Dweik, H., and Akkawi, M. (2009). Highly upregulated in liver cancer noncoding RNA is overexpressed in hepatic colorectal metastasis. Eur. J. Gastroenterol. Hepatol. 21, 688-692. doi: 10.1097/MEG.0b013e328306a3a2

Matouk, I. J., DeGroot, N., Mezan, S., Ayesh, S., Abu-lail, R., Hochberg, A., et al. (2007). The H19 noncoding RNA is essential for human tumor growth. PLoS ONE 2:e845. doi: 10.1371/journal.pone.0000845

Matouk, I. J., Mezan, S., Mizrahi, A., Ohana, P., Abu-Lail, R., Fellig, Y., et al. (2010). The oncofetal H19 RNA connection: hypoxia, p53 and cancer. Biochim. Biophys. Acta 1803, 443-451. doi: 10.1016/j.bbamcr.2010.01.010

Mercer, T. R., Dinger, M. E., Sunkin, S. M., Mehler, M. F., and Mattick, J. S. (2008). Specific expression of long noncoding RNAs in the mouse brain. Proc. Natl. Acad. Sci. U.S.A. 105, 716-721. doi: 10.1073/pnas.0706729105

Mourtada-Maarabouni, M., Pickard, M. R., Hedge, V. L., Farzaneh, F., and Williams, G. T. (2009). GAS5, a non-protein-coding RNA, controls apoptosis and is downregulated in breast cancer. Oncogene 28, 195-208. doi: 10.1038/onc. 2008.373

Müller, S., Zirkel, D., Westphal, M., and Zumkeller, W. (2000). Genomic imprinting of IGF2 and H19 in human meningiomas. Eur. J. Cancer 36, 651-655. doi: 10.1016/S0959-8049(99)00328-7

Nakagawa, T., Endo, H., Yokoyama, M., Abe, J., Tamai, K., Tanaka, N., et al. (2013). Large noncoding RNA HOTAIR enhances aggressive biological behavior and is associated with short disease-free survival in human non-small cell lung cancer. Biochem. Biophys. Res. Commun. 436, 319-324. doi: 10.1016/j.bbrc.2013. 05.101

Okazaki, Y., Furuno, M., Kasukawa, T., Adachi, J., Bono, H., Kondo, S., et al. (2002). Analysis of the mouse transcriptome based on functional annotation of 60,770 full-length cDNAs. Nature 420, 563-573. doi: 10.1038/nature01266

Pandey, G. K., Mitra, S., Subhash, S., Hertwig, F., Kanduri, M., Mishra, K., et al. (2014). The risk-associated long noncoding RNA NBAT-1 controls neuroblastoma progression by regulating cell proliferation and neuronal differentiation. Cancer Cell 26, 722-737. doi: 10.1016/j.ccell.2014.09.014

Panzitt, K., Tschernatsch, M. M., Guelly, C., Moustafa, T., Stradner, M., Strohmaier, H. M., et al. (2007). Characterization of HULC, a novel gene with striking upregulation in hepatocellular carcinoma, as noncoding RNA. Gastroenterology 132, 330-342. doi: 10.1053/j.gastro.2006.08.026

Petrovics, G., Zhang, W., Makarem, M., Street, J. P., Connelly, R., Sun, L., et al. (2004). Elevated expression of PCGEM1, a prostate-specific gene with cell growth-promoting function, is associated with high-risk prostate cancer patients. Oncogene 23, 605-611. doi: 10.1038/sj.onc.1207069

Ponjavic, J., Ponting, C. P., and Lunter, G. (2007). Functionality or transcriptional noise? Evidence for selection within long noncoding RNAs. Genome Res. 17, 556-565. doi: 10.1101/gr.6036807 
Ponting, C. P., and Belgard, T. G. (2010). Transcribed dark matter: meaning or myth? Hum. Mol. Genet. 19, R162-R168. doi: 10.1093/hmg/ddq362

Prensner, J. R., Iyer, M. K., Balbin, O. A., Dhanasekaran, S. M., Cao, Q., Brenner, J. C., et al. (2011). Transcriptome sequencing across a prostate cancer cohort identifies PCAT-1, an unannotated lincRNA implicated in disease progression. Nat. Biotechnol. 29, 742-749. doi: 10.1038/nbt.1914

Properzi, F., Logozzi, M., and Fais, S. (2013). Exosomes: the future of biomarkers in medicine. Biomark. Med. 7, 769-778. doi: 10.2217/bmm.13.63

Qi, P., Xu, M. D., Ni, S. J., Shen, X. H., Wei, P., Huang, D., et al. (2014). Down-regulation of ncRAN, a long noncoding RNA, contributes to colorectal cancer cell migration and invasion and predicts poor overall survival for colorectal cancer patients. Mol. Carcinog. 9, 1039-1045. doi: 10.1002/mc. 22137

Qiao, H. P., Gao, W. S., Huo, J. X., and Yang, Z. S. (2013). Long noncoding RNA GAS5 functions as a tumor suppressor in renal cell carcinoma. Asian Pac. J. Cancer Prev. 14, 1077-1082. doi: 10.7314/APJCP.2013.14.2.1077

Raposo, G., and Stoorvogel, W. (2013). Extracellular vesicles: exosomes, microvesicles, and friends. J. Cell Biol. 200, 373-383. doi: 10.1083/jcb.201 211138

Ravasi, T., Suzuki, H., Pang, K. C., Katayama, S., Furuno, M., Okunishi, R., et al. (2006). Experimental validation of the regulated expression of large numbers of noncoding RNAs from the mouse genome. Genome Res. 16, 11-19. doi: $10.1101 /$ gr.4200206

Ren, S., Wang, F., Shen, J., Sun, Y., Xu, W., Lu, J., et al. (2013). Long noncoding RNA metastasis associated in lung adenocarcinoma transcript 1 derived miniRNA as a novel plasma-based biomarker for diagnosing prostate cancer. Eur. J. Cancer 49, 2949-2959. doi: 10.1016/j.ejca.2013.04.026

Renganathan, A., Kresoja-Rakic, J., Echeverry, N., Ziltener, G., Vrugt, B., Opitz, I., et al. (2014). GAS5 long noncoding RNA in malignant pleural mesothelioma. Mol. Cancer 13:119. doi: 10.1186/1476-4598-13-119

Rinn, J. L., Kertesz, M., Wang, J. K., Squazzo, S. L., Xu, X., Brugmann, S. A., et al. (2007). Functional demarcation of active and silent chromatin domains in human HOX loci by noncoding RNAs. Cell 129, 1311-1323. doi: 10.1016/j.cell.2007.05.022

Schwarzenbach, H., Hoon, D. S., and Pantel, K. (2011). Cell-free nucleic acids as biomarkers in cancer patients. Nat. Rev. Cancer 11, 426-437. doi: 10.1038/nrc3066

Shao, Y., Ye, M., Jiang, X., Sun, W., Ding, X., Liu, Z., et al. (2014). Gastric juice long noncoding RNA used as a tumor marker for screening gastric cancer. Cancer 120, 3320-3328. doi: 10.1002/cncr.28882

Shi, X., Sun, M., Liu, H., Yao, Y., Kong, R., Chen, F., et al. (2013). A critical role for the long noncoding RNA GAS5 in proliferation and apoptosis in non-small-cell lung cancer. Mol. Carcinog. doi: 10.1002/mc.22120 [Epub ahead of print].

Sun, M., Jin, F. Y., Xia, R., Kong, R., Li, J. H., Xu, T. P., et al. (2014). Decreased expression of long noncoding RNA GAS5 indicates a poor prognosis and promotes cell proliferation in gastric cancer. BMC Cancer 14:319. doi: 10.1186/1471-2407-14-319

Svoboda, M., Slyskova, J., Schneiderova, M., Makovicky, P., Bielik, L., Levy, M., et al. (2014). HOTAIR long noncoding RNA is a negative prognostic factor not only in primary tumors, but also in the blood of colorectal cancer patients. Carcinogenesis 35, 1510-1515. doi: 10.1093/carcin/bgu055

Takahashi, K., Yan, I. K., Kogure, T., Haga, H., and Patel, T. (2014). Extracellular vesicle-mediated transfer of long noncoding RNA ROR modulates chemosensitivity in human hepatocellular cancer. FEBS Open Bio. 4, 458-467. doi: 10.1016/j.fob.2014.04.007

Tang, H., Wu, Z., Zhang, J., and Su, B. (2013). Salivary lncRNA as a potential marker for oral squamous cell carcinoma diagnosis. Mol. Med. Rep. 7, 761-766. doi: 10.3892/mmr.2012.1254

Tinzl, M., Marberger, M., Horvath, S., and Chypre, C. (2004). DD3PCA3 RNA analysis in urine-a new perspective for detecting prostate cancer. Eur. Urol. 46, 182-186. doi: 10.1016/j.eururo.2004.06.004

Tripathi, V., Ellis, J. D., Shen, Z., Song, D. Y., Pan, Q., Watt, A. T., et al. (2010). The nuclear-retained noncoding RNA MALAT1 regulates alternative splicing by modulating SR splicing factor phosphorylation. Mol. Cell 39, 925-938. doi: 10.1016/j.molcel.2010.08.011

Tsang, W. P., Ng, E. K., Ng, S. S., Jin, H., Yu, J., Sung, J. J., et al. (2010). Oncofetal H19-derived miR-675 regulates tumor suppressor RB in human colorectal cancer. Carcinogenesis 31, 350-358. doi: 10.1093/carcin/bgp181
Tu, Z. Q., Li, R. J., Mei, J. Z., and Li, X. H. (2014). Down-regulation of long noncoding RNA GAS5 is associated with the prognosis of hepatocellular carcinoma. Int. J. Clin. Exp. Pathol. 7, 4303-4309.

Ulaner, G. A., Vu, T. H., Li, T., Hu, J. F., Yao, X. M., Yang, Y., et al. (2003). Loss of imprinting of IGF2 and $\mathrm{H} 19$ in osteosarcoma is accompanied by reciprocal methylation changes of a CTCF-binding site. Hum. Mol. Genet. 12, 535-549. doi: $10.1093 / \mathrm{hmg} / \mathrm{ddg} 034$

Wang, L., Zeng, X., Chen, S., Ding, L., Zhong, J., Zhao, J. C., et al. (2013). BRCA1 is a negative modulator of the PRC2 complex. EMBO J. 32, 1584-1597. doi: 10.1038/emboj.2013.95

Wang, P., Ren, Z., and Sun, P. (2012). Overexpression of the long noncoding RNA MEG3 impairs in vitro glioma cell proliferation. J. Cell Biochem. 113, 1868-1874. doi: 10.1002/jcb.24055

Wang, X., Arai, S., Song, X., Reichart, D., Du, K., Pascual, G., et al. (2008). Induced ncRNAs allosterically modify RNA-binding proteins in cis to inhibit transcription. Nature 454, 126-130. doi: 10.1038/nature06992

Wang, X. S., Zhang, Z., Wang, H. C., Cai, J. L., Xu, Q. W., Li, M. Q., et al. (2006). Rapid identification of UCA1 as a very sensitive and specific unique marker for human bladder carcinoma. Clin. Cancer Res. 12, 4851-4858. doi: 10.1158/1078-0432.CCR-06-0134

White, N. M., Cabanski, C. R., Silva-Fisher, J. M., Dang, H. X., Govindan, R., and Maher, C. A. (2014). Transcriptome sequencing reveals altered long intergenic noncoding RNAs in lung cancer. Genome Biol. 15:429. doi: 10.1186/s13059-014$0429-8$

Wu, Y., Zhang, L., Wang, Y., Li, H., Ren, X., Wei, F., et al. (2014a). Long noncoding RNA HOTAIR involvement in cancer. Tumour Biol. 35, 9531-9538. doi: 10.1007/s13277-014-2523-7

Wu, Z. H., Wang, X. L., Tang, H. M., Jiang, T., Chen, J., Lu, S., et al. (2014b). Long noncoding RNA HOTAIR is a powerful predictor of metastasis and poor prognosis and is associated with epithelial-mesenchymal transition in colon cancer. Oncol. Rep. 32, 395-402. doi: 10.3892/or.2014.3186

Xie, H., Ma, H., and Zhou, D. (2013). Plasma HULC as a promising novel biomarker for the detection of hepatocellular carcinoma. Biomed. Res. Int. 2013:136106. doi: 10.1155/2013/136106

Xu, Z. Y., Yu, Q. M., Du, Y. A., Yang, L. T., Dong, R. Z., Huang, L., et al. (2013). Knockdown of long noncoding RNA HOTAIR suppresses tumor invasion and reverses epithelial-mesenchymal transition in gastric cancer. Int. J. Biol. Sci. 9, 587-597. doi: 10.7150/ijbs.6339

Yamada, K., Kano, J., Tsunoda, H., Yoshikawa, H., Okubo, C., Ishiyama, T., et al. (2006). Phenotypic characterization of endometrial stromal sarcoma of the uterus. Cancer Sci. 97, 106-112. doi: 10.1111/j.1349-7006.2006. 00147.x

Yang, Z., Zhou, L., Wu, L. M., Lai, M. C., Xie, H. Y., Zhang, F., et al. (2011). Overexpression of long noncoding RNA HOTAIR predicts tumor recurrence in hepatocellular carcinoma patients following liver transplantation. Ann. Surg. Oncol. 18, 1243-1250. doi: 10.1245/s10434-011-1581-y

Yarmishyn, A. A., Batagov, A. O., Tan, J. Z., Sundaram, G. M., Sampath, P., Kuznetsov, V. A., et al. (2014). HOXD-AS1 is a novel lncRNA encoded in HOXD cluster and a marker of neuroblastoma progression revealed via integrative analysis of noncoding transcriptome. BMC Genomics 15(Suppl. 9):S7. doi: 10.1186/1471-2164-15-S9-S7

Ying, L., Chen, Q., Wang,Y., Zhou, Z., Huang, Y., and Qiu, F. (2012). Upregulated MALAT-1 contributes to bladder cancer cell migration by inducing epithelial-to-mesenchymal transition. Mol. Biosyst. 8, 2289-2294. doi: $10.1039 / \mathrm{c} 2 \mathrm{mb} 25070 \mathrm{e}$

Yoon, J. H., Abdelmohsen, K., Srikantan, S., Yang, X., Martindale, J. L., De, S., et al. (2012). LincRNA-p21 suppresses target mRNA translation. Mol. Cell 47, 648-655. doi: 10.1016/j.molcel.2012.06.027

Yu, M., Ohira, M., Li, Y., Niizuma, H., Oo, M. L., Zhu, Y., et al. (2009). High expression of ncRAN, a novel noncoding RNA mapped to chromosome 17q25.1, is associated with poor prognosis in neuroblastoma. Int. J. Oncol. 34, 931-938.

Zhang, S., Chen, S., Yang, G., Gu, F., Li, M., Zhong, B., et al. (2014). Long noncoding RNA HOTAIR as an independent prognostic marker in cancer: a meta-analysis. PLoS ONE 9:e105538. doi: 10.1371/journal.pone.0105538

Zhang, X., Gejman, R., Mahta, A., Zhong, Y., Rice, K. A., Zhou, Y., et al. (2010). Maternally expressed gene 3, an imprinted noncoding RNA gene, is associated with meningioma pathogenesis and progression. Cancer Res. 70, 2350-2358. doi: 10.1158/0008-5472.CAN-09-3885 
Zhang, X. Q., Sun, S., Lam, K. F., Kiang, K. M., Pu, J. K., Ho, A. S., et al. (2013). A long noncoding RNA signature in glioblastoma multiforme predicts survival. Neurobiol. Dis. 58, 123-131. doi: 10.1016/j.nbd.2013.05.011

Zhang, X., Sun, S., Pu, J. K., Tsang, A. C., Lee, D., Man, V. O., et al. (2012). Long noncoding RNA expression profiles predict clinical phenotypes in glioma. Neurobiol. Dis. 48, 1-8. doi: 10.1016/j.nbd.2012.06.004

Zhao, J., Sun, B. K., Erwin, J. A., Song, J. J., and Lee, J. T. (2008). Polycomb proteins targeted by a short repeat RNA to the mouse X chromosome. Science 322, 750-756. doi: 10.1126/science. 1163045

Zheng, H. T., Shi, D. B., Wang, Y. W., Li, X. X., Xu, Y., Tripathi, P., et al. (2014). High expression of lncRNA MALAT1 suggests a biomarker of poor prognosis in colorectal cancer. Int. J. Clin. Exp. Pathol. 7, 3174-3181.

Zhou, Y., Zhong, Y., Wang, Y., Zhang, X., Batista, D. L., Gejman, R., et al. (2007). Activation of p53 by MEG3 noncoding RNA. J. Biol. Chem. 282, 24731-24742. doi: 10.1074/jbc.M702029200
Zhu, Y., Yu, M., Li, Z., Kong, C., Bi, J., Li, J., et al. (2011). ncRAN, a newly identified long noncoding RNA, enhances human bladder tumor growth, invasion, and survival. Urology 77:e1-e5. doi: 10.1016/j.urology.2010. 09.022

Conflict of Interest Statement: The authors declare that the research was conducted in the absence of any commercial or financial relationships that could be construed as a potential conflict of interest.

Copyright (c) 2015 Yarmishyn and Kurochkin. This is an open-access article distributed under the terms of the Creative Commons Attribution License (CC BY). The use, distribution or reproduction in other forums is permitted, provided the original author(s) or licensor are credited and that the original publication in this journal is cited, in accordance with accepted academic practice. No use, distribution or reproduction is permitted which does not comply with these terms. 